\title{
Desenvolvimento de plantas de coentro em função da força iônica da solução nutritiva
}

\author{
Development of coriander plants according to the ionic \\ strength of nutrient solution
}

Leirson Salvador Bezerra de Vasconcelos ${ }^{1 *}$, Egídio Bezerra Neto², Clīstenes Willians Araújo do Nascimento ${ }^{3}$, Levy Paes Barreto ${ }^{2}$

RESUMO: O coentro é uma cultura de grande importância socioeconômica e é encontrado principalmente no Nordeste e no Norte do Brasil. A concentração dos nutrientes da solução nutritiva é característica importante para o desenvolvimento das plantas e uma das formas de mensurá-la é pela condutividade elétrica, que se relaciona ao teor de sais solúveis. O presente trabalho foi conduzido em casa de vegetação e objetivou avaliar o crescimento e o metabolismo do coentro em função da concentração iônica de duas soluções nutritivas, em cultivo hidropônico. Os tratamentos constaram de um arranjo fatorial $(7 \times 2)$, sendo sete níveis de condutividade elétrica e duas soluções nutritivas com quatro repetições, totalizando 56 unidades experimentais. As soluções nutritivas utilizadas foram as de Castellane e de Furlani, com modificações para obter a condutividade elétrica desejada. As plantas foram coletadas após 60 dias do plantio. A solução que produziu maior quantidade de massa verde e seca foi a de Furlani. Os teores de clorofila e carboidratos apresentaram uma tendência de aumento destes compostos proporcional ao incremento da condutividade elétrica. De modo geral, a condutividade elétrica alterou a concentração dos macronutrientes. Assim, é válido que as soluções originais podem ser utilizadas para a produção de coentro hidropônico.

PALAVRAS-CHAVE: Coriandrum sativum, hidroponia, produtividade, macronutrientes, clorofila, carboidratos.
ABSTRACT: Coriander is a culture of great socioeconomic importance. It is primarily found in the North and Northeast regions of Brazil. The concentration of nutrients in the nutrient solution is an important characteristic for the development of plants, and one way to measure it is by the electrical conductivity that is related to the amount of soluble salts. This work was carried out in greenhouse and aimed to evaluate the growth and metabolism of cilantro as a function of the ionic concentration of two nutrient solutions in hydroponics. The treatments were conducted in a $(7 \times 2)$ factorial arrangement, seven levels of electrical conductivity and two nutrient solutions, with four replicates, totalling 56 experimental units. Castellane and Furlani nutrient solutions with modifications to obtain the desired electrical conductivity were used. The plants were harvested 60 days after planting. Furlani solution produced the highest values of fresh and dry weight. The contents of chlorophyll and carbohydrates increased as electrical conductivity increased. In general, electrical conductivity alters the concentration of macronutrients. Thus, original solutions can be used for the hydroponic production of coriander. KEYWORDS: Coriandrum sativum, hydroponics, productivity, macronutrients, chlorophyll, carbohydrates.

\section{Introdução}

O coentro (Coriandrum sativum L.) é uma hortaliça condimentar amplamente utilizada no Brasil (TRIGO; TRIGO; PIEROBOM, 1997; TORRES et al., 2012), sendo cultivada principalmente no Nordeste e no Norte do país (PEREIRA et al., 2011). É uma cultura de clima quente, intolerante a baixas temperaturas, podendo ser semeada ao 
longo do ano em baixa altitude. É pouco exigente em relação ao solo e tolerante à acidez (FILGUEIRA, 2002). Devido à sua exploração comercial por um grande número de produtores, a cultura apresenta grande importância socioeconômica para essas regiões (MEDEIROS et al., 1998; NASCIMENTO et al., 2006). Em vários Estados do Nordeste, o cultivo do coentro é uma atividade de notável alcance social, chegando a se constituir na principal fonte de renda de várias comunidades rurais. O município de Vitória de Santo Antão-PE é considerado o maior produtor de coentro do Brasil (KANECO, 2006).

Segundo Haag e Minami (1998), por ser uma cultura de ciclo curto (45-60 dias), garante retorno rápido do capital investido, aumentando a renda das famílias envolvidas na sua exploração. Souza et al. (2011) apontam que grande número de produtores envolve-se na produção desta hortaliça, tornando-a, consequentemente, de relevante importância econômica.

Seu cultivo visa à obtenção de massa verde, bastante utilizada na culinária em diversos pratos, além da produção de frutos secos, para a utilização nas indústrias farmacêutica e alimentícia (BARROS JUNIOR et al., 2004).

A hidroponia é uma técnica de cultivo de plantas sem a utilização de solos, de forma que os nutrientes minerais são disponibilizados às plantas através de uma solução nutritiva balanceada para o desenvolvimento de cada cultura (APRÍGIO et al., 2012), propiciando vantagens para o produtor, como obtenção de produtos de alta qualidade, ciclo mais curto e redução do uso de insumos agrícolas (PAULUS; DOURADO NETO; PAULUS, 2012).

Analisando-se o crescimento do cultivo hidropônico no mundo, Resh (1996) comenta a crescente expansão desta técnica, que tem permitido o cultivo em locais cujos solos são improdutivos, tornando estes locais em verdadeiros mananciais de alimentos hortícolas. Alves et al. (2011) destacam a melhor eficiência do uso da água, devido à redução nas perdas por evaporação, além de reduzir os impactos ambientais na produção de hortaliças, associados ao acúmulo de sais no solo.

O cultivo hidropônico tem ocupado cada vez mais espaço na produção de hortaliças devido à possibilidade de cultivo em pequenas áreas, bem como em locais onde as condições de solo são limitantes ao cultivo convencional (JUNQUEIRA; LIMA; PEIXOTO, 1997). O conhecimento prévio sobre substratos e espécies a serem cultivadas, bem como sobre a solução nutritiva e suas condições ideais para o plantio, são essenciais para o sucesso do cultivo hidropônico. Nesta técnica, o substrato tem a função principal de fornecer à planta sustentação. Dentre as características desejáveis dos substratos, destacam-se: custo, disponibilidade, capacidade de troca de cátions, esterilidade biológica, aeração, retenção de umidade, boa agregação às raízes e uniformidade (GONÇALVES, 1995).
A concentração e o balanceamento dos nutrientes na solução nutritiva são características muito importantes para o desenvolvimento das plantas. Para cultivos hidropônicos, é usual estimar o teor de nutrientes na solução de forma indireta, medindo sua condutividade elétrica (VERDONCK; VLEESCHAUWER; BOODT, 1981). Segundo Bliska Júnior e Honório (1996), a avaliação da condutividade elétrica tem sido recomendada para a reposição de nutrientes na solução nutritiva, mas não identifica a faixa crítica de nutrientes e quais estão em falta ou em excesso. Como a solução é composta, em geral, por íons minerais, o nível estimado da concentração desses nutrientes pode ser obtido medindo-se a capacidade da solução nutritiva de conduzir corrente elétrica, ou seja, quanto maior a concentração dos íons, maior será a capacidade da solução nutritiva de conduzir corrente elétrica (STAFF, 1998).

A condutividade elétrica está diretamente relacionada ao teor de sais solúveis, que, estando em valores inadequados, pode afetar negativamente o desenvolvimento das plantas (KÄMPF; FERMINO, 2000). Para o cultivo hidropônico de coentro, ainda são inexistentes as informações referentes à concentração ideal de nutrientes na solução. Deste modo, fazem-se necessários estudos sobre o balanço nutricional, bem como sobre a condutividade elétrica da solução nutritiva, visando a um melhor desempenho na produção desta hortaliça.

Diante das premissas apresentadas, o presente trabalho teve como objetivo avaliar, em condições de casa de vegetação, o desenvolvimento do coentro em função da força iônica de duas soluções nutritivas.

\section{Material e Métodos}

O experimento foi conduzido na Casa de Vegetação, Departamento de Química, área de Química Agrícola, da Universidade Federal Rural de Pernambuco, com temperatura média de $28{ }^{\circ} \mathrm{C}$ e umidade relativa do ar de $85 \%$. A espécie em estudo foi o coentro, cultivar Verdão.

$\mathrm{O}$ experimento foi conduzido em vasos com volume de $10 \mathrm{dm}^{3}$, contendo $8 \mathrm{dm}^{3}$ de substrato. O substrato utilizado foi uma mistura na proporção de 3:1 de pó-de-coco e um substrato comercial (formado por três partes iguais: moinha de carvão vegetal, casca de pinho desestabilizada e vermiculita). O substrato, antes do cultivo, foi submetido a análises químicas, conforme a Tabela 1. Para a determinação do $\mathrm{pH}$, utilizou-se água na relação de 1:2,5; de $\mathrm{Ca}, \mathrm{Mg}$ e Al, extrator $\mathrm{KCl} 1 \mathrm{~mol} / \mathrm{L}$; de $\mathrm{P}, \mathrm{Na}$ e K, Mehlich 1, e de $\mathrm{H}+\mathrm{Al}$, extrator acetato de cálcio 0,5 molcL - pH 7,0 (EMBRAPA, 1999).

No fundo dos vasos, foi adicionado cerca de $1 \mathrm{~cm}$ de brita de espessura fina, para drenagem através de um orifício de $0,5 \mathrm{~cm}$ de diâmetro, localizado na porção inferior dos vasos. Os tratamentos constaram de um arranjo fatorial $(7 \times 2)$, sendo

Tabela 1. Análise do substrato utilizado no experimento.

\begin{tabular}{ccccccc}
\hline $\mathbf{p h}$ & $\mathbf{P}$ & $\mathbf{N a}^{+}$ & $\mathbf{K}^{+}$ & $\mathbf{C a}^{+2}$ & $\mathbf{M g}^{+2}$ & $\mathbf{A l}^{+3}$ \\
\hline$(\mathbf{a} g u a-\mathbf{1 : 2 , 5})$ & $\left(\mathbf{m g} / \mathbf{d m}^{\mathbf{3}}\right)$ & & $-\cdots+\mathbf{H}^{+}+\mathbf{A l}^{+3}$ & \\
\hline 6,3 & 22 & 0,44 & 0,19 & 0,00 & 0,06 & 0,00 \\
\hline
\end{tabular}


sete níveis de condutividade elétrica $(0,0 ; 0,5 ; 1,0 ; 1,5 ; 2,0$; 2,5 e 3,0 dS.m ${ }^{-1}$ ) e duas soluções nutritivas (CASTELLANE; ARAÚJO, 1994; FURLANI et al., 1998) com quatro repetições, totalizando 56 unidades experimentais.

O preparo das soluções nutritivas se deu da seguinte forma: foram, inicialmente, preparadas as soluções de maior condutividade elétrica; em seguida, foram realizadas diluições, nas proporções cujo resultado final era a condutividade desejada. Para confirmar a CE das soluções, averiguou-se utilizando condutivímetro digital. $\mathrm{O} \mathrm{pH}$ das soluções de cultivo foi de 6,0 , tendo sido corrigido, quando necessário. Para identificar a concentração dos nutrientes, foram realizados cálculos utilizando-se os dados iniciais da solução de maior condutividade elétrica e as proporções de diluição (Tabela 2).

A semeadura foi realizada diretamente nos vasos, sendo que em cada vaso foram colocadas 32 sementes, em oito orifícios com cerca de $1,0 \mathrm{~cm}$ de profundidade, com todos os orifícios equidistantes. Após a emissão da segunda folha definitiva, foi efetuado um desbaste, deixando-se 16 plantas por vaso. Durante este período, as plantas foram irrigadas com água destilada. Após o desbaste, foram iniciados os tratamentos. As plantas foram irrigadas com solução nutritiva, até o início da drenagem. O líquido drenado foi desprezado.
Aos 60 dias após o plantio, foi realizada a coleta das plantas, que foram pesadas, acondicionadas em sacos de papel e, em seguida, colocadas para secar em estufa com circulação de ar, a uma temperatura de $65{ }^{\circ} \mathrm{C}$ até atingir peso constante. Em seguida, procedeu-se à determinação da biomassa total.

Para a análise de clorofilas $a$ e $b$ (ARNON, 1949), foi preparado um extrato da parte aérea fresca com etanol a $80 \%$. Com uma alíquota do extrato etanólico, foi realizada a cromatografia de partição, visando a evitar a interferência dos pigmentos na análise de carboidratos. No extrato aquoso, foi realizada a análise de carboidratos solúveis totais (BEZERRA NETO; BARRETO, 2004).

As amostras secas foram trituradas em moinhos de facas tipo Wiley e analisadas quanto aos teores de potássio, cálcio, enxofre, fósforo e magnésio, após digestão nitroperclórica. A determinação de potássio foi feita por fotometria de emissão de chamas (FEC); de cálcio e magnésio, por espectrofotometria de absorção atômica (EAA); de fósforo, por espectrofotometria de luz visível, e de enxofre, por turbidimetria, conforme descrito por Malavolta, Vitti e Oliveira (1989) e Miyazawa, Pavan e Bloch (1984). Para a determinação de nitrogênio, utilizou-se o método de Kjeldahl, segundo Malavolta, Vitti e Oliveira (1989). Os dados obtidos

Tabela 2. Concentração de nutrientes e condutividade elétrica nas soluções nutritivas de Castellane e Furlani.

\begin{tabular}{|c|c|c|c|c|c|c|c|c|c|c|c|c|c|}
\hline & \multicolumn{13}{|c|}{ Solução Nutritiva de Castellane e Araújo (1994) } \\
\hline & $\mathrm{N}-\mathrm{NO}_{3}$ & $\mathrm{~N}-\mathrm{NH}_{4}$ & $\mathbf{P}$ & $\mathbf{K}$ & $\mathrm{Ca}$ & Mg & $\mathbf{S}$ & B & Mo & $\mathrm{Cu}$ & $\mathrm{Zn}$ & $\mathbf{F e}$ & Mn \\
\hline C.E. & \multicolumn{7}{|c|}{ mg.L -1 $^{-1}$} & \multicolumn{6}{|c|}{$\mu$ g. $\mathbf{L}^{-1}$} \\
\hline 0,0 & 0 & - & 0 & 0 & 0 & 0 & 0 & 0 & 0 & 0 & 0 & 0 & 0 \\
\hline 0,5 & 46,14 & - & 12,02 & 82,58 & 31,21 & 4,65 & 6,20 & 58,15 & 9,69 & 9,69 & 58,15 & 969,23 & 77,54 \\
\hline 1,0 & 87,08 & - & 22,68 & 155,86 & 58,91 & 8,78 & 11,71 & 109,76 & 18,29 & 18,29 & 109,76 & 1829,37 & 146,35 \\
\hline 1,5 & 148,87 & - & 38,78 & 266,46 & 100,73 & 15,01 & 20,02 & 187,65 & 31,27 & 31,27 & 187,65 & 3127,44 & 250,19 \\
\hline 2,0 & 188,79 & - & 49,18 & 337,91 & 127,71 & 19,04 & 25,38 & 237,97 & 39,66 & 39,66 & 237,97 & 3966,08 & 317,29 \\
\hline 2,5 & 243,53 & - & 63,44 & 435,91 & 164,74 & 24,56 & 32,74 & 306,98 & 51,16 & 51,16 & 306,98 & 5116,25 & 409,30 \\
\hline 3,0 & 288,06 & - & 75,04 & 515,60 & 194,86 & 29,05 & 38,73 & 363,10 & 60,52 & 60,52 & 363,10 & 6051,63 & 484,13 \\
\hline \multicolumn{14}{|c|}{ Concentração da Solução Nutritiva Original e sua CE original } \\
\hline 2,48 & 238 & - & 62 & 426 & 161 & 24 & 32 & 300 & 50 & 50 & 300 & 5000 & 400 \\
\hline & \multicolumn{13}{|c|}{ Solução Nutritiva de Furlani et al. (1998) } \\
\hline & $\mathrm{N}-\mathrm{NO}_{3}$ & $\mathrm{~N}-\mathrm{NH}_{4}$ & $\mathbf{P}$ & $\mathbf{K}$ & $\mathbf{C a}$ & Mg & $\mathbf{S}$ & B & Mo & $\mathrm{Cu}$ & Zn & $\mathrm{Fe}$ & Mn \\
\hline C.E. & \multicolumn{7}{|c|}{ mg.L -1 $^{-1}$} & \multicolumn{6}{|c|}{$\mu$ g. $\mathbf{L}^{-1}$} \\
\hline 0,0 & 0 & 0 & 0 & 0 & 0 & 0 & 0 & 0 & 0 & 0 & 0 & 0 & 0 \\
\hline 0,5 & 35,02 & 4,83 & 7,85 & 36,83 & 28,58 & 7,65 & 10,47 & 60,37 & 12,07 & 4,03 & 12,07 & 402,49 & 80,49 \\
\hline 1,0 & 82,04 & 11,32 & 18,39 & 86,28 & 66,95 & 17,92 & 24,52 & 141,44 & 28,29 & 9,42 & 28,29 & 942,96 & 188,59 \\
\hline 1,5 & 129,05 & 17,80 & 28,93 & 135,73 & 105,32 & 28,18 & 38,57 & 222,50 & 44,50 & 14,83 & 44,50 & 1483,34 & 296,67 \\
\hline 2,0 & 176,06 & 24,28 & 39,46 & 185,17 & 143,68 & 38,45 & 52,62 & 303,56 & 60,71 & 20,23 & 60,71 & 2023,73 & 404,75 \\
\hline 2,5 & 223,08 & 30,77 & 50,00 & 234,62 & 182,05 & 48,72 & 66,67 & 384,62 & 76,92 & 25,64 & 76,92 & 2564,11 & 512,82 \\
\hline 3,0 & 270,09 & 37,26 & 60,54 & 284,06 & 220,42 & 58,99 & 80,72 & 465,67 & 93,14 & 31,05 & 93,14 & 3104,50 & 620,90 \\
\hline \multicolumn{14}{|c|}{ Concentração da Solução Nutritiva Original e sua CE original } \\
\hline 1,84 & 174 & 24 & 39 & 183 & 142 & 38 & 52 & 300 & 60 & 20 & 60 & 2000 & 400 \\
\hline
\end{tabular}


foram submetidos à análise de variância utilizando o software SAEG (UNIVERSIDADE..., 2000).

\section{Resultados e Discussão}

\section{Produção de matéria fresca e seca}

A produção de matéria fresca apresentou resposta quadrática, com o aumento da condutividade elétrica nas soluções nutritivas trabalhadas (Figura 1). Os valores para a produção de matéria fresca na solução de Castellane foram de 0,$531 ; 0,717 ; 0,791 ; 0,938 ; 0,992$ e 0,718 g planta $^{-1}$, para as CE de 0,$5 ; 1,0 ; 1,5 ; 2,0 ; 2,5$ e $3,0 \mathrm{dS} . \mathrm{m}^{-1}$, respectivamente. Observe-se que ocorreu a produção máxima estimada na CE na solução nutritiva de $2,07 \mathrm{dS} . \mathrm{m}^{-1}$, condutividade esta bem próxima da original na solução nutritiva de Castellane, mostrando, assim, que essa solução é adequada para o cultivo desta hortaliça, sem necessidade de diluição. Em relação à solução nutritiva de Furlani, foram encontrados os seguintes valores para a produção de matéria fresca: 0,$367 ; 0,930 ; 1,335$; 0,$855 ; 0,584$ e 0,552 g planta $^{-1}$ para as CE de 0,5; 1,0; 1,5; 2,0; 2,5 e 3,0 dS.m ${ }^{-1}$, respectivamente. A produção máxima estimada de matéria fresca foi quando a $\mathrm{CE}$ da solução nutritiva foi de 1,63 dS.m ${ }^{-1}$ (Figura 1). A condutividade original da solução nutritiva de Furlani é de $1,84 \mathrm{dS} . \mathrm{m}^{-1}$; logo, esta se encontra elevada para a produção máxima de coentro, nas condições em que o trabalho foi realizado.

Savvas e Lenz (1996) e Souza et al. (2005), trabalhando com berinjela, encontraram maior estimativa de produtividade da parte vegetativa na solução com condutividade elétrica de 2,10 e 2,36 dS.m ${ }^{-1}$, respectivamente. Rocha, Peil e Cogo (2010), em estudo com tomate-cereja, identificaram a máxima eficiência técnica (MET) para peso médio de frutos, com 1,9 dS.m ${ }^{-1}$. Estes resultados mostram que os tratamentos aplicados foram suficientes para a averiguação de nível crítico na produção de biomassa fresca do coentro, que, neste trabalho, foi de 1,86 dS. $\mathrm{m}^{-1}$ para a solução de Castellane.

Para a produção de matéria seca das plantas cultivadas na solução de Castellane, foram encontrados os seguintes valores: 0,$089 ; 0,326 ; 0,479 ; 0,498 ; 0,633$ e 0,493 g planta $^{-1}$ para as CE de 0,$5 ; 1,0 ; 1,5 ; 2,0 ; 2,5$ e $3,0 \mathrm{dS} . \mathrm{m}^{-1}$, respectivamente; note-se que a produção máxima estimada de matéria seca deu-se na CE da solução nutritiva de 2,14 dS.m ${ }^{-1}$ (Figura 1). Para as plantas cultivadas na solução de Furlani, os valores encontrados para matéria seca variaram de 0,082 a 1,335 g planta $^{-1}$ (Figura 1). As plantas cultivadas na solução de Furlani mostraram-se mais sensíveis ao aumento da condutividade elétrica, pois, desde a condutividade de $2,0 \mathrm{dS} \cdot \mathrm{m}^{-1}$, notou-se uma redução na produção de matéria seca, enquanto que, na solução de Castellane, esta redução foi notada apenas na última condutividade trabalhada. Andriolo et al. (2005), trabalhando com alface, concluíram que, acima de 2,6 dS.m ${ }^{-1}$, a massa fresca foi reduzida. Este valor elevado pode ser explicado pela formulação da solução nutritiva e pela cultivar de alface trabalhada.

Grangeiro et al. (2003), trabalhando com rúcula em sistema hidropônico, encontraram maior peso seco em valores próximos de condutividade - 2,3 e 2,6 dS.m ${ }^{-1}$ - analisados
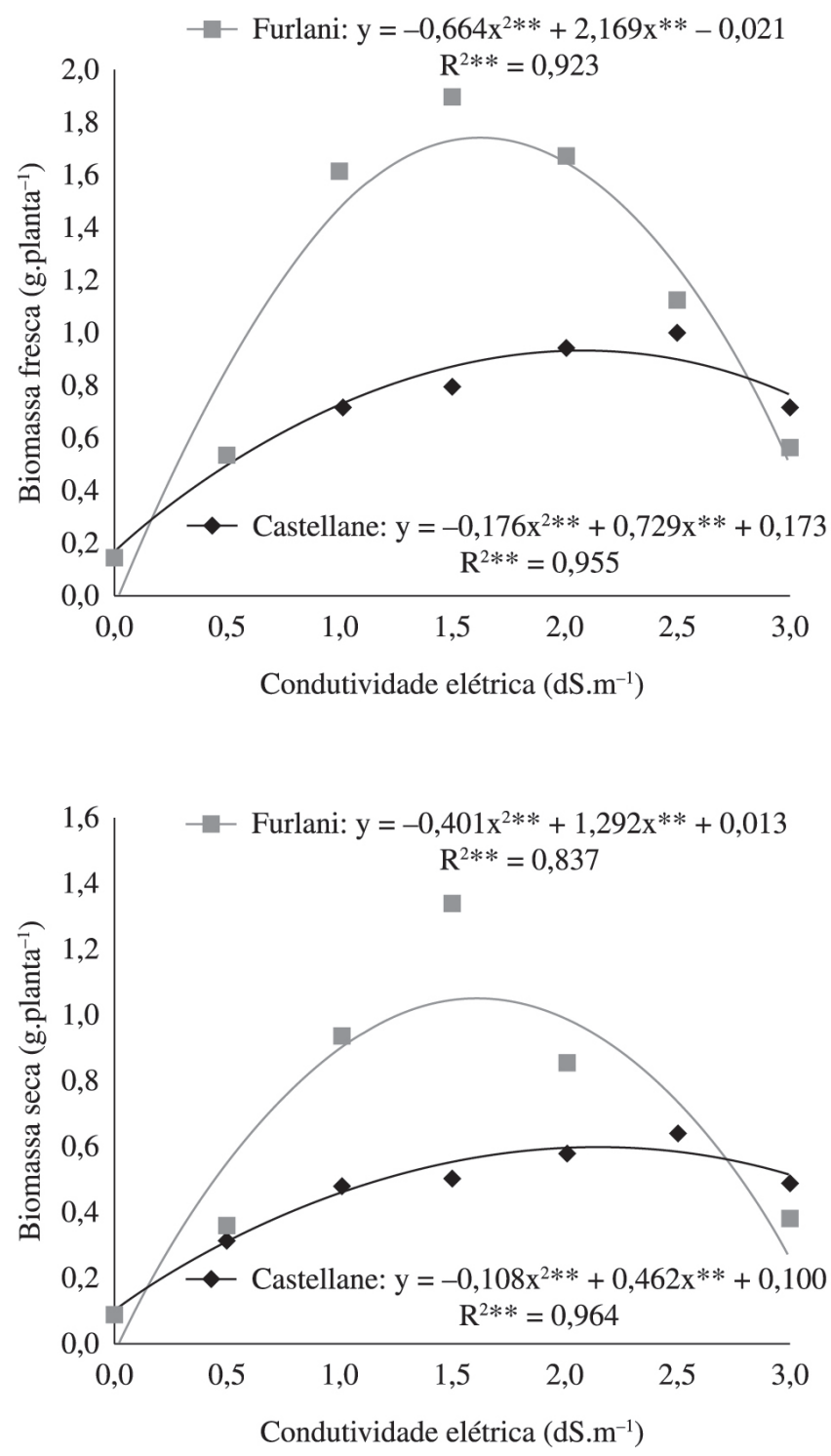

Figura 1. Biomassa fresca-PMF e biomassa seca-PMS de plantas de coentro cultivadas com diferentes níveis de condutividade elétrica $\left(\mathrm{dS} . \mathrm{m}^{-1}\right)$, em duas soluções nutritivas.

neste trabalho. Portela, Peil e Rombaldi (2012), em cultivo de morangueiro, encontraram maior peso seco de material vegetativo com condutividade de $1,5 \mathrm{dS} \cdot \mathrm{m}^{-1}$. Costa et al. (2001) encontraram maior produção de matéria fresca em alface quando a condutividade elétrica da solução era de $2,46 \mathrm{dS} . \mathrm{m}^{-1}$, valor próximo ao encontrado no presente trabalho. Os valores encontrados para a maior produção de biomassa, utilizando a solução nutritiva de Castellane, neste trabalho, foram de 2,07 e 2,14 dS. $\mathrm{m}^{-1}$ para biomassa fresca e seca, respectivamente. Todos estes resultados levam a concluir que a maior produção de biomassa fresca e seca de hortaliças se encontra na faixa de 1,5 a $2,5 \mathrm{dS} . \mathrm{m}^{-1}$.

Os tratamentos 0,0 e 3,0 dS. $\mathrm{m}^{-1}$ foram os que menos produziram matéria fresca e seca. Resultado semelhante foi encontrado por Souza et al. (2005), quando trabalharam com alfavaca, ao observarem uma redução na produção de biomassa fresca e seca nos tratamentos de menor e maior força iônica na 
solução nutritiva. Pode-se observar que o emprego de soluções nutritivas com condutividades baixas ou muito elevadas provocou uma redução significativa na produção de matéria fresca e seca. Tal fato encontra-se relacionado à interferência na nutrição oriunda de uma menor disponibilidade de nutrientes ou pelo elevado potencial osmótico, o qual acarreta menor absorção de água e, consequentemente, de nutrientes.

Quando comparadas as duas soluções nutritivas, as produções de matéria fresca e seca foram maiores para a solução de Furlani, quando sua condutividade elétrica chegou a $1,5 \mathrm{dS} \cdot \mathrm{m}^{-1}$.

\section{Concentração de clorofilas}

Quanto à concentração de clorofila, o tratamento com condutividade zero obteve os menores valores, um resultado já esperado, pois tal tratamento era desprovido de qualquer nutriente (Figura 2). Com relação às soluções trabalhadas, não houve diferença significativa entre estas. Porém, a concentração de clorofila foi mais sensível na solução Castellane, pois quando se aumentou a condutividade elétrica, houve redução da produção do pigmento a partir da concentração de $1,5 \mathrm{dS} . \mathrm{m}^{-1}$, resultado que se destaca com a menor produção de biomassa verde, utilizando esta solução com condutividade de 3,0 dS.m ${ }^{-1}$. Os níveis de condutividade elétrica trabalhados interferiram na produção deste pigmento, concordando com literatura consultada, que relata: quanto maior a concentração de magnésio, maior é a produção de clorofila.

As plantas sem adubação apresentaram menores teores de clorofila, mostrando-se até mesmo com clorose, assim como Lima et al. (2001) constataram em plantas de feijão deficientes em nitrogênio. Esse resultado pode ser esperado em vista de que clorofila e o nitrogênio se correlacionam positivamente (MALAVOLTA; VITTI; OLIVEIRA, 1997). Paulus et al. (2010), trabalhando com alface, sob estresse salino, em hidroponia, com diferentes níveis de condutividade elétrica, identificaram um aumento linear na concentração deste pigmento, como forma de regulação da pressão osmótica da planta com o meio. Na solução de Castellane, este fenômeno mostrou-se mais evidenciado.

\section{Concentração de carboidratos}

$\mathrm{O}$ teor de carboidratos seguiu a mesma tendência do teor de clorofila no tratamento sem a presença de nutrientes, pois se obteve a menor concentração deste soluto orgânico
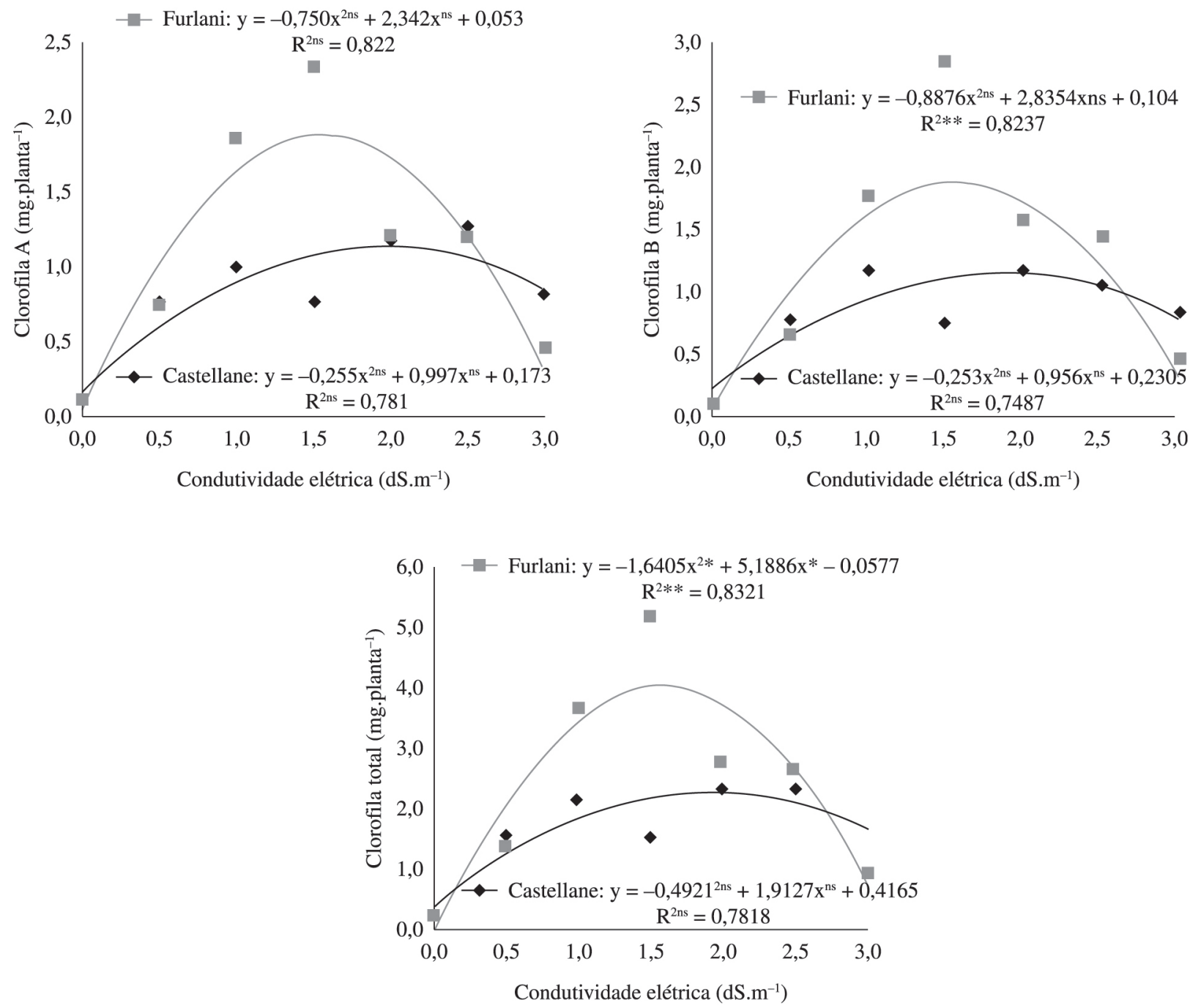

Figura 2. Conteúdo de clorofila $a, b$ e total na parte aérea do coentro cultivado sob diferentes níveis de condutividade elétrica em duas soluções nutritivas. 
(Figura 3); contudo, entre as soluções, houve diferenças significativas nos tratamentos intermediários: 1,0, 1,5 e 2,0 dS.m ${ }^{-1}$. Diferentemente do teor de clorofila, as plantas cultivadas na solução nutritiva de Furlani foram mais sensíveis quanto ao aumento de carboidratos, sendo o valor máximo obtido no tratamento $1,5 \mathrm{dS} \cdot \mathrm{m}^{-1}$, enquanto que, na solução de Castellane, o maior acúmulo foi encontrado no tratamento 2,5 dS.m ${ }^{-1}$ (Figura 3).

Uma das formas de as plantas tolerarem altas concentrações de nutrientes é o acúmulo de solutos orgânicos, pois estes auxiliam no ajustamento osmótico; citam-se, entre esses solutos, os carboidratos solúveis totais (GARCIA et al., 1997). Apesar de não conclusiva, a quantificação deste soluto auxilia no estudo sobre o crescimento do vegetal. Quando relacionados o teor de carboidratos e a produção de matéria fresca e seca, percebeu-se que os maiores valores destas variáveis se encontram no mesmo tratamento e que existe um teor limítrofe de condutividade elétrica, a partir do qual se desencadeia o acúmulo deste composto. Porém, possivelmente não ocorreu ajustamento osmótico, pois, apesar do aumento no teor de carboidratos, a produção de biomassa fresca e seca foi inversamente proporcional ao aumento da concentração de nutrientes na solução nutritiva.

\section{Concentração de nutrientes}

As maiores concentrações de nitrogênio, fósforo, potássio, magnésio e cálcio, nas plantas de coentro cultivadas na solução nutritiva de Castellane, foram na CE 2,0 dS.m ${ }^{-1}$. Para enxofre, as plantas acumularam mais na $\mathrm{CE}$ de $2,5 \mathrm{dS} . \mathrm{m}^{-1}$ da solução de Castellane. Já as maiores concentrações de potássio, fósforo, nitrogênio e cálcio, nas plantas cultivadas na solução nutritiva de Furlani, foram encontradas na CE de 1,5 dS.m ${ }^{-1}$ (Figura 4).

Possivelmente, a quantidade de nitrogênio fornecida não foi suficiente para promover modificações nas suas concentrações, pois a cultura responde mais ao fornecimento de nitrogênio. Sua deficiência retarda o crescimento da planta, as folhas mais velhas ficam totalmente amarelas. Todavia, o excesso de nitrogênio é altamente prejudicial, podendo tornar-se tóxico, além de dificultar a absorção de outros nutrientes (GARCIA; MINAMI; DECHEN, 1982; KATAYAMA, 1993; FILGUEIRA, 2002). Nenhuma destas situações foi encontrada neste trabalho.

Quanto ao fósforo, especificamente, as quantidades exigidas são geralmente baixas, principalmente quando comparadas com o nitrogênio e o potássio. Entretanto, apesar dessa baixa exigência, a resposta às doses de fertilizantes é geralmente alta (NOVAIS; SMYTH, 1999).

Filgueiras, Takahashi e Beninni (2002), trabalhando com alface, encontraram os menores valores de nitrogênio, potássio e enxofre na solução com condutividade $1,0 \mathrm{dS} . \mathrm{m}^{-1}$, resultado igual ao encontrado neste trabalho, em que os menores valores para nitrogênio e potássio foram encontrados no tratamento $0,0 \mathrm{dS} \cdot \mathrm{m}^{-1}$ e, para enxofre, no tratamento $0,5 \mathrm{dS} . \mathrm{m}^{-1}$, ou seja, nos tratamentos com as menores concentrações de nutrientes. Pode-se concluir que os menores valores destes nutrientes foram encontrados nos tratamentos cuja condutividade elétrica da solução nutritiva apresentou o menor valor.

Filgueiras, Takahashi e Beninni (2002), após revisarem vários trabalhos referentes ao antagonismo entre íons, verificaram que, na maioria das vezes, o potássio possui uma maior habilidade competitiva do que os outros cátions, e que o decréscimo no teor de potássio devido à alta concentração de outros cátions não é tão pronunciado como é o efeito de potássio sobre a absorção de cálcio ou magnésio.

Souza et al. (2005), trabalhando com berinjela e diferentes níveis de condutividade elétrica, encontraram a mesma tendência de aumento para o íon potássio e de redução para o magnésio, concomitantemente ao aumento da condutividade elétrica. Reafirma-se, portanto, que estes íons são antagônicos (MALAVOLTA, 2006).

De modo geral, a condutividade elétrica alterou a concentração dos macronutrientes, porém não provocou distúrbios no vegetal, já que nenhum dos íons avaliados teve seus valores negativos ou em excesso, para a cultura do coentro. Assim, é válido que as soluções originais podem ser utilizadas para a produção de coentro hidropônico.

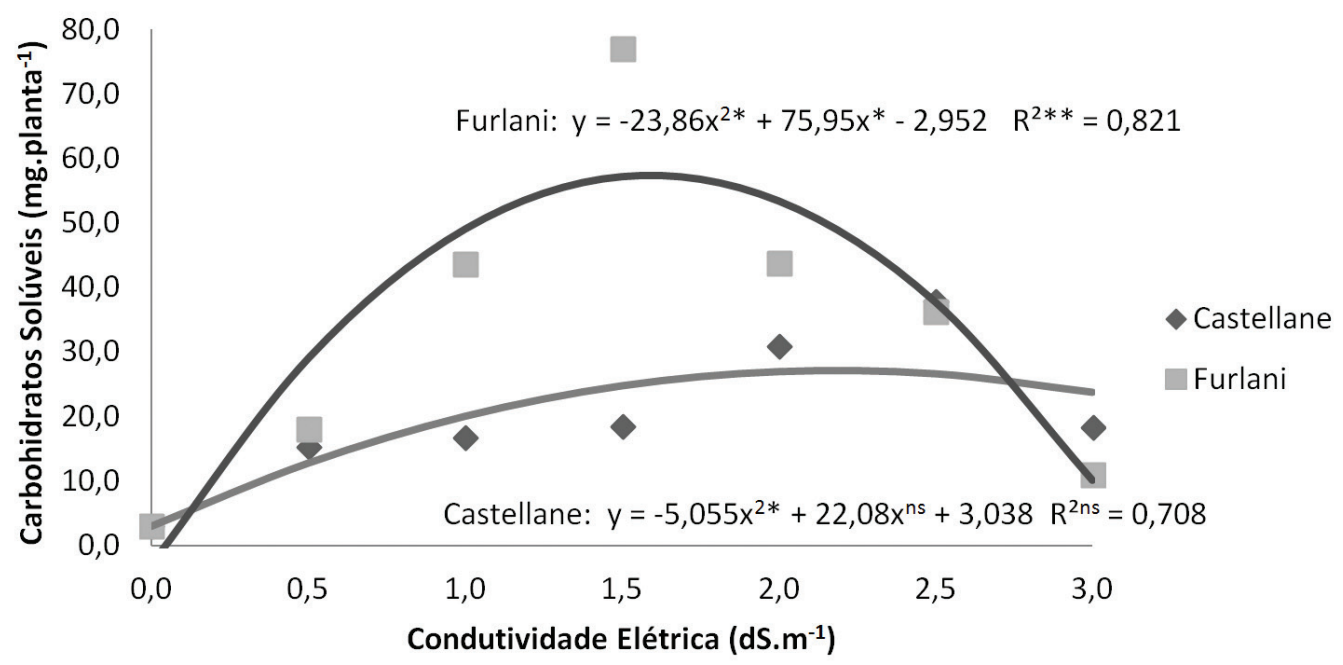

Figura 3. Conteúdo de carboidratos solúveis totais na parte aérea do coentro cultivado sob diferentes níveis de condutividade elétrica em duas soluções nutritivas. 

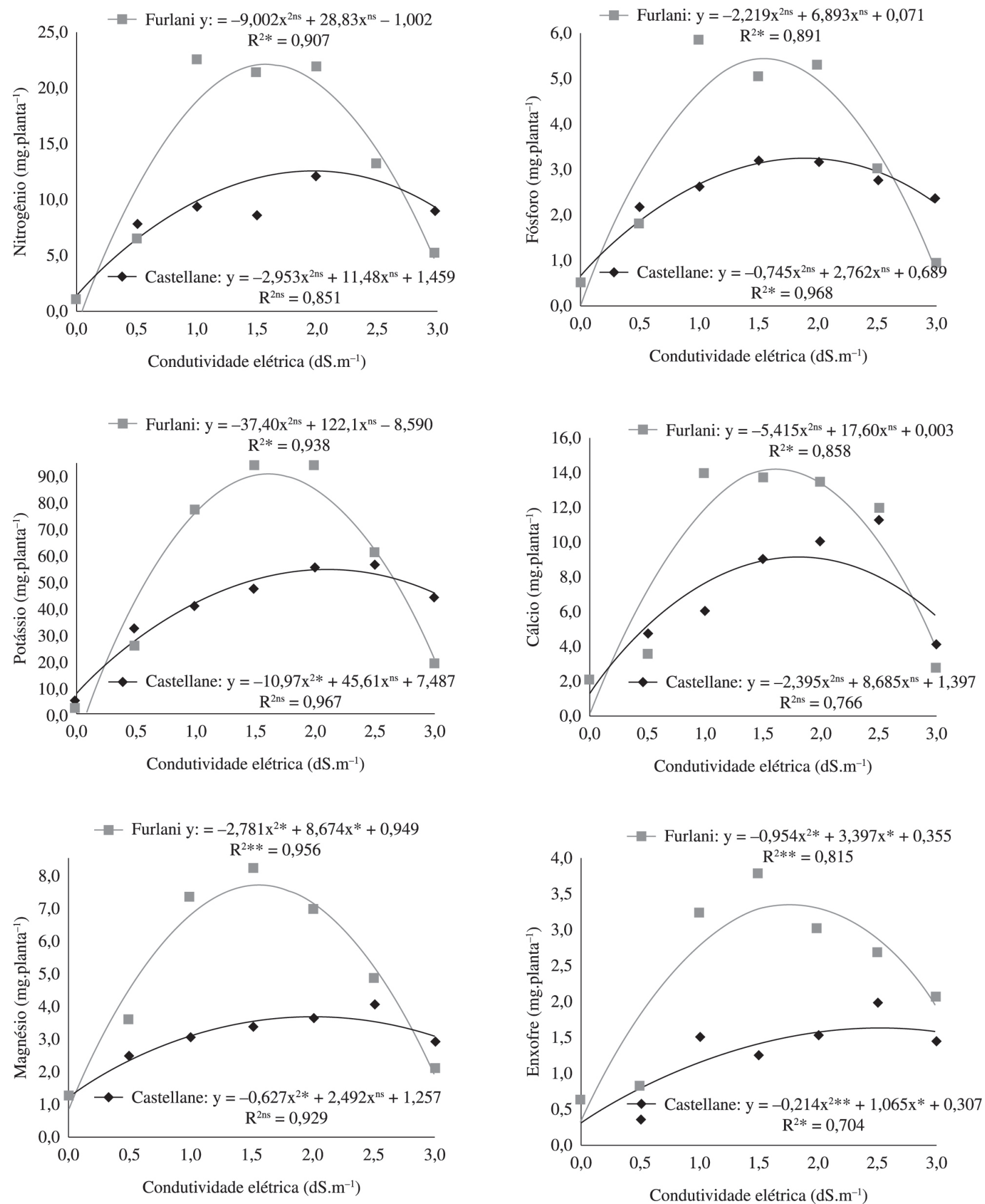

Figura 4. Conteúdo de nitrogênio $(\mathrm{N})$, fósforo $(\mathrm{P})$, potássio $(\mathrm{K})$, cálcio $(\mathrm{Ca})$, magnésio $(\mathrm{Mg})$ e enxofre $(\mathrm{S})$ na parte aérea de plantas de coentro cultivadas em soluções nutritivas de Castellane e Furlani, com sete diferentes níveis de condutividade elétrica.

\section{Conclusões}

O estudo das respostas bioquímicas e nutricionais de hortaliças, bem como os dados de seu crescimento quando submetidas a diferentes concentrações de nutrientes, ainda é escasso, principalmente quando se trata de uma espécie com grande variabilidade quanto às características de interesse agronômico. As respostas do coentro às diferentes soluções nutritivas encontradas nesta pesquisa comprovam a necessidade de mais estudos nesta área.

De um modo geral, a solução de Furlani proporcionou maior produção de biomassa fresca e seca, porém as plantas foram mais sensíveis ao aumento da condutividade elétrica 
nesta solução nutritiva, quando comparada à solução nutritiva de Castellane.

O acúmulo de açúcares, tão amplamente relatado na literatura por colaborar com mais de $50 \%$ dos solutos envolvidos no ajustamento osmótico de várias espécies, não foi observado no coentro. Apenas observou-se uma tendência de aumento nos açúcares em níveis de condutividade superiores a 1,5 dS.m ${ }^{-1}$ na solução nutritiva de Furlani, enquanto que, na solução nutritiva de Castellane, não houve diferenças significativas.

O potencial osmótico das soluções nutritivas, estimado em termos de condutividade elétrica, alterou a concentração dos macronutrientes, porém não provocou distúrbios no vegetal, uma vez que nenhum dos íons avaliados teve seus valores deficientes ou em excesso, para a cultura do coentro. Assim, é válido que as soluções originais podem ser utilizadas para a produção de coentro hidropônico.

Portanto, é recomendável o uso de soluções de concentração iônica original para o cultivo de coentro, nas condições climáticas em que foi desenvolvido este trabalho.

\section{Referências}

ANDRIOLO, J. L. et al. Growth and yield of lettuce plants under salinity. Horticultura Brasileira, v. 23, p. 931-934, 2005. http:// dx.doi.org/10.1590/S0102-05362005000400014

ALVES, M. S. et al. Estratégias de uso de água salobra na produção de alface em hidroponia NFT. Revista Brasileira de Engenharia Agrícola e Ambiental, v. 15, n. 5, p. 491-498, 2011. http://dx.doi. org/10.1590/S1415-43662011000500009

APRÍGIO, A. et al. Teor de nitrato em alface hidropônica em função de vazões e períodos de pós-colheita. Revista Brasileira de Engenharia Agrícola e Ambiental, v. 16, n. 9, p. 946-951, 2012. http://dx.doi.org/10.1590/S1415-43662012000900004

ARNON, D. I. Cooper enzymes in isolated chloroplasts: polyphrenol oxidase in Beta vulgaris. Plant Physiology, v. 24, p. 1-15, 1949. PMid:16654194 PMCid:PMC437905. http://dx.doi.org/10.1104/ pp.24.1.1

BARROS JUNIOR, A. P. et al. Desempenho agronômico de cultivares comerciais de coentro em cultivo solteiro sob condições de temperatura elevada e ampla luminosidade. Caatinga, v. 17, n. 2 , p. 82-86, 2004.

BEZERRA NETO, E.; BARRETO, L. P. Métodos de análises químicas em plantas. Recife: UFRPE, 2004. 149 p.

BLISKA JUNIOR, A.; HONÓRIO, S. L. Cartilha Tecnológica de Hidroponia. Campinas: Unicamp, 1996. 43 p.

CASTEllane, P. D.; ARAúJo, J. A. C. Cultivo sem solo: Hidroponia. Jaboticabal: FUNEP, 1994. 43 p.

COSTA, P. C. et al. Condutividade elétrica da solução nutritiva e produção de alface em hidroponia. Scientia Agricola, v. 58 , n. 3, p. 595-597, 2001. http://dx.doi.org/10.1590/S010390162001000300023

EMBRAPA. Manual de análises químicas de solos, plantas e fertilizantes. $1999.370 \mathrm{p}$.

FILGUEIRA, F. A. R. Novo Manual de Olericultura: agrotecnologia moderna na produção e comercialização de hortaliças. Viçosa: UFV, 2002. 402 p.
FILGUEIRAS, R. C.; TAKAHASHI, H. W.; BENINNI, E. R. Y. Produção de alface hidropônico em diferentes condutividades elétricas. Semina: Ciências Agrárias, v. 23, p. 157-164, 2002.

FURLANI, P. R. et al. Nutrição mineral de hortaliças, preparo e manejo de soluções nutritivas. Revista Informe Agropecuário, v. 20, n. 200-201, p. 90-98, 1998.

GARCIA, A. B. et al. Effects of osmoprotectants upon $\mathrm{NaCl}$ stress in rice. Plant Physiology, v. 115, p. 159-169, 1997. PMid:12223797 PMCid:PMC158471.

GARCIA, L. L. C.; MINAMI, K.; DECHEN, A. R. Nutrição mineral de hortaliças, XLIX. Concentração e acúmulo de macronutrientes em alface (Lactuca sativa L.) cv. Brasil 48 e Clause's Aurélia. Anais da Escola Superior de Agricultura "Luiz de Queiroz", v. 39, p. 455-484, 1982. http://dx.doi.org/10.1590/S007112761982000100027

GONÇALVES, A. L. Recipientes, embalagens e acondicionamentos de mudas de plantas ornamentais. In: MINAMI, K. (Ed.). Produção de mudas de alta qualidade em horticultura. São Paulo: T.A. Queiroz, 1995. 128 p.

GRANGEIRO, L. C. et al. Produção de rúcula em hidroponia com diferentes concentrações de cobre. Horticultura Brasileira, v. 21, p. 69-72, 2003. http://dx.doi.org/10.1590/S010205362003000100014

HAAG, H. P.; MINAMI, K. Nutrição mineral de hortaliças. Campinas: Fundação Cargill, 1998. 29 p.

JUNQUEIRA, A. M. R.; LIMA, J. A.; PEIXOTO, J. R. Hidroponia: cultivo sem solo. Brasília: UnB, 1997. 31 p.

KÄMPF, A. N.; FERMINO, H. H. (Ed.). Substratos para plantas: a base da produção vegetal em recipientes. Porto Alegre: Genesis, 2000. 312 p.

KANECO, M. G. Produção de coentro e cebolinha em substratos regionais da Amazônia à base de madeira em decomposição (Paú). 2006. 58 f. Dissertação (Mestrado)-Universidade de Brasília, Brasília, 2006.

KATAYAMA, M. Nutrição e adubação da alface, chicória e almeirão. In: FERREIRA, M. E.; CASTELLANE, P. D.; CRUZ, M. C. P. Nutrição de hortaliças. Piracicaba: Associação Brasileira para Pesquisa da Potassa e do Fosfato, 1993. p. 141-148.

LIMA, E. V. et al. Adubação NK no desenvolvimento e na concentração de macronutrientes no florescimento do feijoeiro. Scientia Agricola, v. 58, p. 125-129, 2001. http://dx.doi. org/10.1590/S0103-90162001000100019

MALAVOLTA, E. Manual de nutrição mineral de plantas. São Paulo: Agronômica Ceres, 2006. 638 p.

MALAVOLTA, E.; VITTI, G. C.; OLIVEIRA, S. A. Avaliação do estado nutricional das plantas: princípios e aplicações. Piracicaba: Potafós, 1989. 201 p.

MALAVOLTA, E.; VITTI, G. C.; OLIVEIRA, S. A. Avaliação do estado nutricional de plantas: princípios e aplicações. Piracicaba: Potafós, 1997. 308 p.

MEDEIROS, J. F. et al. Efeitos da qualidade da água de irrigação sobre o coentro cultivado em substrato inicialmente salino. Revista Brasileira de Engenharia Agrícola e Ambiental, n. 2, p. 22-26, 1998

MIYAZAWA, M.; PAVAN, M. A.; BLOCH, M. F. M. Avaliação de métodos com e sem digestão para a extração de elementos em tecidos de plantas. Ciência e Cultura, v. 36, p. 1953-1958, 1984.

NASCIMENTO, W. M. et al. Colheita e armazenamento de sementes de coentro. Pesquisa Agropecuária Brasileira, v. 41, n. 12 , p. 1793-1801, 2006. http://dx.doi.org/10.1590/S0100204X2006001200015 
NOVAIS, R. F.; SMYTH, T. J. Fósforo em solo e planta em condições tropicais. Viçosa, 1999. 399 p. PMid:9987841.

PAULUS, D. et al. Produção e indicadores fisiológicos de alface sob hidroponia com água salina. Horticultura Brasileira, v. 28 , n. 1 , p. $29-35,2010$. http://dx.doi.org/10.1590/S010205362010000100006

PAULUS, D.; DOURADO NETO, D. D.; PAULUS, E. Análise sensorial, teores de nitrato e de nutrientes de alface cultivada em hidroponia sob águas salinas. Horticultura Brasileira, v. 30 , n. 1 , p. $18-25,2012$. http://dx.doi.org/10.1590/S010205362012000100004

PEREIRA, M. F. S. et al. Qualidade fisiológica de sementes de coentro [Coriandrum sativum (L.)]. Revista Brasileira de Plantas Medicinais, v. 13, p. 518-522, 2011. Número especial.

PORTELA, I. P.; PEIL, R. M. N.; ROMBALDI, C. V. Efeito da concentração de nutrientes no crescimento, produtividade e qualidade de morangos em hidroponia. Horticultura Brasileira, v. 30, n. 2, p. 266-273, 2012. http://dx.doi.org/10.1590/S010205362012000200014

RESH, H. M. Hydroponic food production. Califórnia: Woodbridge Press, 1996. $527 \mathrm{p}$.

ROCHA, M. Q.; PEIL, R. M. N.; COGO, C. M. Rendimento do tomate cereja em função do cacho floral e da concentração de nutrientes em hidroponia. Horticultura Brasileira, v. 28, n. 4, p. 466-471, 2010. http://dx.doi.org/10.1590/S0102-05362010000400015
SAVVAS, D.; LENZ, F. Influence and $\mathrm{NaCl}$ concentration in the nutrient solutions on mineral composition of eggplants grown in sand culture. Angewandte Botany, v. 70, p. 124-127, 1996.

SOUZA, T. V. et al. Época de colheita e qualidade fisiológica de sementes de coentro produzidas no Norte de Minas Gerais. Revista Brasileira de Plantas Medicinais, v. 13, p. 591-597, 2011. Número especial. http://dx.doi.org/10.1590/S1516-05722011000500015

SOUZA, V. S. et al. Influência da condutividade elétrica da solução nutritiva na acumulação de matéria seca e teores de nutrientes em berinjela cultivada em pó de coco. Revista Ciência Agronômica, v. 36, p. 123-128, 2005.

STAFF, H. Hidroponia. Cuiabá: SEBRAE/MT, 1998.

TORRES, S. B. et al. Deterioração controlada em sementes de coentro. Revista Brasileira de Sementes, v. 34, n. 2, p. 319-316, 2012. http://dx.doi.org/10.1590/S0101-31222012000200018

TRIGO, M. F. O. O.; TRIGO, L. F. N.; PIEROBOM, C. R. Fungos associados às sementes de coentro (Coriandrum sativum L.) no Rio Grande do Sul. Revista Brasileira de Sementes, n. 19, p. 214-218, 1997.

UNIVERSIDADE FEDERAL DE VIÇOSA - UFV. SAEG - Sistema de análises estatísticas e genéticas (Versão 9.0). Viçosa: UFV, 2000. 150 p. (Manual do usuário).

VERDONCK, O.; VLEESCHAUWER, D.; BOODT, M. The influence of the substrate to plant growth. Acta Horticulturae, v. 126, p. 251-258, 1981. 